\title{
INFORMATION MODELLING AND MANAGEMENT IN HISTORICAL CONTEXTS: AN ITALIAN CASE STUDY
}

\author{
IVANO GRAZIANO LAVENIA \\ Istituto di Scienze del Patrimonio Culturale (ISPC), Italian National Research Council (CNR), \\ Università degli Studi di Catania, Italy
}

\begin{abstract}
European and Mediterranean cities and landscapes are complex territorial systems characterized by an inestimable cultural and natural heritage, which can particularly benefit from holistic approaches for their sustainable development. Nowadays, digital tools and innovative methods can provide valuable support to pursue the above-mentioned target. Based on both methodological research and practical application, the paper presents a BIM-based lifecycle-oriented approach to information modelling and management of an existing building set in an urban historical context. Investigating advanced software solutions and workflows in the preparatory phases of a building project, it takes into account, as integral parts of a BIM ecosystem, not only the technological aspects, but also the process and organisational/ cultural ones.
\end{abstract}

Keywords: built and natural environment, sustainability, cultural heritage, building information modelling, BIM-GIS integration, common date environment, database management system.

\section{INTRODUCTION}

Information management and interoperability for buildings and infrastructures are crucial to increase the productivity in the AECOO industry and to enable a sustainable development of complex territorial systems. Integrated three-dimensional data management for urban spaces and critical infrastructures is already significant for several purposes (Becker et al. [1]). Fostering decision-making processes, interdisciplinary collaboration and knowledge sharing, they have become more important within the legislative and regulatory framework developed in various European countries due to the European Directive 2014/24/EU (Gigliarelli et al. [2]).

In Italy, this directive was transposed into national law through the Public Contract Code (Legislative Decree 50/2016). Article 23 of this decree introduced the use of "specific digital methods and tools, such as modelling for buildings and infrastructures" for new construction as well as for conservation and rehabilitation projects, prioritizing the complex ones.

Laws and regulations that incentivize seismic and energy retrofitting as well as urban renewal encourage investments in this direction too, since the definition of BIM-oriented strategies for buildings and infrastructures set in a wider territorial context can facilitate different activities. Among others, Biagini and Arslan [3] and various authors identify: seismic risk reduction; energy efficiency improvement; facility management; monitoring; Internet of Things (IoT) services; environmental sustainability assessment; decontamination; deconstruction; selective substitution of pre-existing objects; time and cost estimation and optimization; conflict detection; stakeholder collaboration; dissemination of cultural heritage information.

According to Kiviniemi [4], the emphasis "is now moving from the design and construction of individual buildings and infrastructures to lifecycle values and complex networks of built and natural heritage, services and users. Emerging Smart City initiatives are combining new technologies into the fabric of cities and data is becoming more and more valuable asset and moving from the monolithic software into distributed resources which can be accessed and utilized on any platform and with any application". 
The growing interest in lifecycle-oriented and data-driven design and construction processes is leading not only from "workstation-oriented" to "cloud-oriented" working procedures and to technological changes, but also to a wider paradigm shift. The testing and consolidation of these innovative methods is still ongoing: despite digital tools solve several problems, they create new challenges (Biagini and Arslan [3]). The AECOO industry has to take into account four important factors for a successful implementation of new methods: technologies, processes, policy and people (Succar [5]). Building information modelling can bring real add-value if these aspects are properly combined. To progress into the mature stage of its implementation, it is necessary to go beyond a mere three-dimensional representation approach (Ciribini et al. [6]). The BS 1192 and the PAS 1192-2/-3, which define the "Common Data Environment (CDE)", as well as the UNI 11337 and the Ministerial Decree 560/2017, which define the "Ambiente di Condivisione Dati (ACDat)", have already put the accent on digital collaboration platforms.

Considering the above, this paper focuses mainly on a pilot project called "SPIDEr" (Strategies for Planning and Integrated DEvelopment of Urban Cultural Contexts) carried out at the Institute for Archaeological and Monumental Heritage (IBAM) of the Italian National Research Council (CNR) (now "Istituto di Scienze del Patrimonio Culturale" (ISPC)) and financed by the European Structural and Investment Funds. The case study is the historic district of the Metropolitan City of Catania, inscribed on the list of the UNESCO's World Heritage Sites with the "Late Baroque Towns of the Val di Noto" since 2002, and the headquarters of the institute, "Palazzo Ingrassia", part of the monumental complex of the former Benedictine Monastery "San Nicolò l'Arena". Investigating different digital tools (BIM, GIS, DBMS) in the preparatory phases of a building project, the research tested a flexible working methodology that aims to facilitate knowledge sharing, interdisciplinary collaboration and decision-making processes for territorial transformations, as well as management, monitoring and promotion of cultural heritage.

\section{THEORETICAL FRAMEWORK}

An effective and efficient management of heterogeneous data in three dimensions requires a digital repository/sharing platform for storing semantically enriched models, objects and documents (Saygi and Remondino [7]).

According to Kolbe and Plümer [8] there are mainly two modelling paradigms:

- the Constructive Solid Geometry (CGS), followed by the Building Information Modelling (BIM) and Industry Foundation Classes (IFC);

- the Boundary Representation (B-Rep), followed by the 3D Geographic Information System (GIS) and CityGML.

Despite an increasingly pressing need of interoperability between these two modelling paradigms and the BIM and GIS platforms, they remain not fully integrated yet. BIM offers advantages in terms of geometric and semantic information, which can span the entire lifecycle of buildings and infrastructures, while GIS is a decision-making tool based on geovisualization (Song et al. [9]). An approach of BIM integration with GIS is proposed by Chenaux et al. [10] and Murphy et al. [11] for Virtual Historic Dublin.

According to López et al. [12], the analysis of the current scientific literature dealing with virtual modelling shows the benefits of using BIM to facilitate the built heritage management processes. With the aim of implementing BIM in historic buildings, Murphy et al. [13] theorized the so-called H-BIM (Historic Building Information Modelling). For the modelling of the Four Courts in Dublin City, Murphy et al. [14] adopted a method based on two workflows: 
- $\quad$ historic reconstruction, the model was created from the historic data;

- procedural reconstruction, the model was developed from the laser scanning survey.

The main differences between a BIM process for a new building and an H-BIM process for an existing building are the nature of the information collected and the genesis and use of the models. A BIM model has a predictive value and responds particularly well to standardized buildings, while an H-BIM model describes the actual state and/or the historical reconstruction of complex existing objects.

The digital restitution of the geometric, constructive and conservative features of cultural heritage can facilitate its management, monitoring and promotion. According to Gigliarelli et al. [15] the convergence of different disciplinary contributions in the conservation processes is consolidating thanks to the use of approaches and technologies in the field of H-BIM, numerical simulations and decision support systems.

The creation of a three-dimensional semantic model of an existing building has to respond to the requirements of the planned interventions and/or of the prefixed objectives. To be more useful for professionals, the model has to take into account not only the external threedimensional surfaces, but also the relationships among the spatial and technical components, as well as the construction phases and techniques, the thicknesses and materials of the latter (Brumana et al. [16]). According to the "Common BIM Requirements 2012" of Building Smart Finland: "Modelling of an existing building is often easiest to conduct at the time the renovation construction project is underway. [...] Modelling accuracy and the level of details in the BIM of an existing building must be agreed on project basis and considered carefully to balance benefits and cost. If the modelling is performed primarily for the needs of facility management software, it can be often restricted to the basic data of spaces and objects". Thomson [17] and other authors, such as Graham et al. [18], have examined this topic too.

A model obtained from a historical reconstruction based on documentation can be further developed using not only primitive geometries, but also point clouds, meshes or NURBS, taking into account the "ReverseLoD" approach theorized by Banfi [19]. Brusaporci et al. [20] distinguish among four workflows:

- use of the simple post-processed point cloud;

- creation of a solid model obtained from the point cloud triangulation;

- $\quad$ automated partial recognition of objects and production of a hybrid model;

- manual reconstruction of objects (often very time-consuming), which can be more or less parametric and more or less intelligent.

Biagini and Arslan [3] report that the main difficulties faced in consolidating H-BIM procedures are generated by the uncertain definition of the modelling purposes. A BIM model has to meet the predefined needs containing the required information despite a simplified geometry. As argued by Biagini and Donato [21], particular attention has to be paid during the creation of the parametric objects.

\section{CASE STUDY}

Commissioned by the Faculty of Medicine and Surgery, "Palazzo Ingrassia" was built between the end of the 19th and the beginning of the 20th centuries on a piece of land next to the north side of the church of the former Benedictine Monastery "San Nicolò l'Arena". The area was granted freely to the University by the Municipality of Catania. During the excavation procedure for the foundation construction, Carmelo Sciuto Patti found some remains of possible Roman baths (Calabrese [22]). 
Due to the damages caused by the eruption of the volcano Etna in 1669 and the disastrous earthquake that struck south-eastern Sicily in 1693, the Benedictine Monastery "San Nicolò l'Arena" was rebuilt based on current layout starting from the 18th century. After the nationalization of the property in the 19th century, it housed various educational institutions and barracks. Acquired by the University of Catania at the end of the 20th century, the complex was restored according to a project of the architect Giancarlo De Carlo, which initially included also "Palazzo Ingrassia" (De Carlo [23]).

Originally, the latter housed the departments of Normal and Pathological Human Anatomy, Hygiene and Forensic Medicine of the Università degli Studi di Catania, previously placed in "Palazzo Tezzano" (seat of the former "San Marco" Hospital) and now located at the University Polyclinic. After some restoration and maintenance works carried out at the beginning of the new millennium, the historic building hosts nowadays not only the headquarters of the research institute IBAM-CNR, but also the Archaeological Museum of the University and some sections of the departments of humanities (DISUM) and education sciences (DISFOR).

Taking into account the related scientific literature, standards and guidelines, as well as the following preparatory phases of a building restoration project:

- documentary and archival research;

- topographical and geometric survey;

- urban, architectural and historical analysis;

- identification of the construction techniques, materials, rooms and areas;

- pre-diagnosis of building defects.

The application of the above-mentioned digital methods and tools (BIM, GIS, DBMS) was carried out through the following activities:

- definition of a shared coding/cataloguing system for heterogeneous data integration and professional collaboration, creation of a relational model for database management;

- $\quad$ setting-up of a storage solution for graphical/non-graphical data and documentation, BIM-GIS-DBMS interoperability;

- document processing and database population;

- geo-referencing and identification of common real-world and project local coordinates;

- BIM-oriented 3D modelling in support of the aforementioned urban, architectural and historical analysis.

3.1 Definition of a shared coding/cataloguing system and creation of a relational model for database management

An optimal management strategy for information, models and objects requires a review of the methods for naming files, classifying building components and/or developing ontologies for cultural heritage, starting from the most common standards. Just to name some of them: ISO 12006-2:2015; UniClass 2015; OmniClass; MasterFormat; Uniformat II; CI/SfB; UNI 8290-1:1981+A122:1983, UNI 10838:1999 and UNI 11337-1:2017; Cataloguing Guidelines of the Central Institute for Cataloguing and Documentation of the Italian MiBAC; ISO 21127:2014.

With the aim to facilitate professional collaboration, a first version of a shared building system classification based on the Italian Standards UNI and CI/SfB was tested. BIM 
authoring software programs, such as Autodesk Revit, can import this and other classifications loading a new "assembly code" text file.

In order to integrate the information gathered through the historic reconstruction and the identification of the construction techniques, materials, rooms and areas of the building with those related to the graphical/non-graphical data sources, a stand-alone interoperable relational database was developed. Based on Structured Query Language (SQL), it was connected to an online server using the Open DataBase Connectivity (ODBC).

The structure of this database was constantly revised to maintain the consistency with the BIM platform. Autodesk Revit can keep track of the information flow through specific "shared parameters", which can link the BIM objects with external files either using a Uniform Resource Locator (URL) or integrating the databases using visual programming tools, such as Dynamo, or plug-ins, such as Revit DB Link. The latter was experimented also in the case study of Parma Cathedral, carried out by Nazarena and Riccardo [24].

\subsection{Setting-up of a storage solution for graphical/non-graphical data and documentation}

To achieve better professional collaboration, knowledge sharing and interoperability among different software programs and platforms (BIM-GIS-DBMS), it was necessary to set-up a specific storage solution.

After the creation of a shared folder in the local network and the configuration of a Network-Attached Storage (NAS) server, a common repository for object-based threedimensional models was arranged. A digital platform capable of fulfilling this role is the one available within Autodesk Revit setting-up the "work-sets" and enabling the "work-sharing" functionality. This functionality allows professionals and stakeholders involved in a project to work simultaneously in a single centralized workplace and to use various cloud-based services on different devices (such as BIM Track). As aforementioned, a bidirectional connection between Autodesk Revit and a database management program, such as SQL Server, can be established through the plug-in Revit DB Link. The latter allows exporting the BIM model data to a database, where they can be further edited and then re-imported into the BIM authoring program. A similar connection can be established with MySQL using Dynamo. As previously mentioned, it is also possible to import new "assembly code" text files for updating and/or changing the building system classification, as well as to create specific "shared parameters" in order to link the external files uploaded to the NAS.

Furthermore, different BIM-GIS integration workflows were tested. A first one, using Autodesk Infraworks and Civil 3D, platforms that can integrate different kinds of models, biand three-dimensional objects, point clouds and shapefiles at a territorial level. A second one, taking advantage of the new Revit reading capabilities of ArcGIS Pro, developed recently thanks to a partnership between Esri and Autodesk, in order to bring the BIM information from the Revit native format into the GIS platform. A third one, converting the BIM model into shapefiles for the GIS analysis. In addition, other software solutions were investigated. Among them: 3DCityDB, a free open source software for the storage, management and visualization of three-dimensional urban models according to the CityGML standard, developed by the Technical University of Munich with other partners and used by Chenaux et al. [10] and Murphy et al. [11] in Virtual Historic Dublin; CesiumJS, an open source JavaScript library for world-class 3D mapping of geospatial data. 


\subsection{Documentary and archival research, document processing and database population}

The digital collaboration platform defined by the Italian BIM Standards (UNI 11337-1:2017) is constituted by both an "Object Library" and a "Common Data Environment", which stores the digital models, objects, data and documentation related to a project. The non-digital data and documentation are firstly stored in a "Data Room" and then, once digitized, included in the "Common Data Environment".

Following this approach, the documentary and archival research (related to the design and construction history of "Palazzo Ingrassia", as well as to the spatial planning and the construction techniques and materials typical of the area of Catania), was complemented by the digitization and systematization of the gathered graphical/non-graphical data. The collected information and files were linked to the BIM platform and/or used for populating the aforementioned database with a unique identifier (UID).

\subsection{Topographical and geometric survey, geo-referencing and identification of coordinates}

The topographical and geometric survey started with the definition of a common spatial reference system and a geo-referencing procedure. It was performed with the support of a total station and a terrestrial laser scanner (3D FARO Focus X 130) accompanied by direct measurements and inspections. The acquired laser scanning data and their post-processing (registration/alignment, geo-referencing, cleaning-up, decimation) allowed gaining a point cloud of the external surface and of the internal western part of the building. The postprocessing can be carried out through different software programs, such as Leica Geosystems HDS Cyclone, FARO Scene, Autodesk ReCap. In addition, photogrammetry (Structure from Motion with software programs such as Agisoft PhotoScan or 3Dflow 3DF Zephir) was used for the surveying and restitution of some archaeological ruins located nearby the building.

The next step was the definition of the real world and different project local coordinates in the BIM authoring software program. This procedure is necessary to maintain the consistency between the GIS and BIM platforms and to coordinate the acquired point clouds with the meshes and/or NURBS obtained through their processing; the CAD files collected or gained through vectorization of raster images; the BIM and other 3D objects and models created. In Autodesk Revit, this means the identification of the "real" and "project north", as well as of the "shared coordinate system" and the agreed local coordinate systems. Extension for Civil 3D and Revit such as Autodesk Shared Reference Point can facilitate these procedures.

\subsection{BIM-oriented 3D modelling in support of urban, architectural and historical analysis}

The further step in digitizing building information was the creation of a BIM model. As for any reverse engineering process, this challenging phase aims to recover the design intent, going beyond the captured point clouds and/or meshes and creating a three-dimensional model made-up of semantic BIM objects. To this end, it is likely that Big Data analytics and Machine Learning algorithms will become increasingly beneficial.

Taking into account the aforementioned method followed by Murphy et al. [14] and other authors (Paris and Wahbeh [25]), as well as the "ReverseLoD" approach theorized by Banfi [19], the modelling process was based on the integration and interaction of CAD files, point 
clouds, meshes, NURBS, BIM and other 3D objects and models. The BIM platform was therefore set-up for the creation of a federated "hybrid" BIM model. Different modelling workflows were adopted, depending on the geometry of the elements. Paris and Wahbeh [25] distinguish among:

- $\quad$ elements with simple (despite stratified) geometries (the most frequent situation);

- elements with complex geometries with recurrent common matrices that can be parameterized;

- $\quad$ elements with complex geometries that can be express mathematically;

- elements with irregular geometries that have predominantly sculptural and/or ruined character.

Once defined the aforementioned common coding/cataloguing and spatial reference systems, the relevant graphical documents gathered through the documentary and archival research were linked to the BIM platform. If they were not available in a CAD file format, they were vectorised and linked in both raster image and CAD file formats. The point clouds were linked successively, when made available.

Based on the digital and/or digitized collected graphical/non-graphical data sources, it was possible to carry out a diachronic reconstruction of the design, construction and transformation dynamics of the building. Once defined the "work-sharing" procedures, some "phases" were created according to the main construction, restoration and maintenance interventions, and a "mass" model of the building volumes was created. The phases were firstly associated to the volumes and sequentially to the created BIM objects.

The next step was the collaborative modelling of BIM objects based on the documentation. At this stage, the geometric reconstruction was mainly based on the plans of the last restoration and maintenance projects, compared with the other available plans and taking into account the symmetries and rules underlying the architectural design. The latter are more important in case of survey inaccessibility issues and damaged architectural heritage. This approach, also supported by GIS and DBMS, facilitates the processes of urban, architectural and historical analysis; identification of construction techniques, materials, rooms and areas (consistently with the chosen shared building system classification); prediagnosis of building defects, which are ordinarily carried out during the preparatory phases of a building restoration project. In this way, it was possible to reach a good level of understanding of the building in its context, as well as a general/global BIM model with a low LoD (Level of Development), which was successively further detailed. The latter included the reconstruction hypothesis of some archaeological remains, which was linked to the federated "hybrid" BIM model. As regards this aspect, specific studies on how BIM models can facilitate the architectural stratigraphic analysis borrowed from Harris Matrix were already carried out (Brusaporci et al. [26]).

The analysis and reconstruction of the "categories" and "types" of building elements; the "profiles" and "pattern" of friezes, decorations and railings; the rooms and the areas were based not only on the documentation related to the building, but also on the one related to the construction techniques and materials spread over the area (scientific literature, manuals, treatises, etc.). This process led to the development of a library of objects and materials, which included the creation of custom patterns for their representation and can be further developed through specific building investigations. This library can be used for similar cases and in the same area to create other BIM models and to carry out simulations that can support decision-making processes (especially if it contains specific parameters, such as thermal transmittance, reflection factor, mechanical resistance, etc.). 
In this regard, it is important to highlight the potential benefits of this approach, which allows different professionals to work simultaneously in a single centralized workplace and to collaborate interdisciplinary in order to enrich and detail the graphical/non-graphical data and documentation related to the semantic BIM objects created. The concepts of Level of Development (LoD), Level of Geometry (LoG) and Level of Information (LoI) have to be taken into due consideration to avoid improper use of the information modelled and/or entered into the database. For this reason and according to the Italian BIM Standards (UNI 11337-4:2017), specific "shared parameters" were created to indicate the LoD, LoG and LoI of the modelled BIM objects.

Particular attention has to be paid to the file size. It has to be kept at manageable level. This is possible, as aforementioned, setting-up the creation of federated "hybrid" BIM models. The accuracy and level of details can be increased using point clouds, meshes and NURBS. The point clouds can be segmented and classified, processed and saved as meshes or NURBS, which can be converted into BIM/IFC format and enriched with attributes or imported using visual programming tools, such as Dynamo (Yang et al. [27]).

The next step was the detailing of the BIM model based on the captured point clouds. As aforementioned, depending on the geometry of the elements, different modelling workflows were adopted. For the elements with simple (despite stratified) geometries, such as walls, floors, columns and beams, manual and semi-automatic workflows were followed. The previously developed BIM objects were adapted to the captured point clouds manually and/or using specific plug-ins, such as FARO As-Built, which can reduce the modelling time. A similar workflow was used for the elements with complex geometries and recurrent common matrices, such as friezes, decorations, railings, windows, doors, which were parameterized.

In this phase, the modelling was simplified taking into account just the significant particularities, alterations and deformations of the building elements, according to the aforementioned "Common BIM Requirements 2012" of Building Smart Finland, Series 2 ("Modelling of the starting situation"), aiming at the accuracy levels of the "inventory models" defined in paragraph 5 ("Modelling requirements"). These tolerances and the "graphic error" of $0.2 \mathrm{~mm}$ were considered to define the most suitable scale for the created sheets. To check the modelling quality, the same plug-in, FARO As-Built, or other software programs, such as CloudCompare, offer the possibility to carry out a "deviation analysis" that compares the created BIM model with the captured point clouds.

In comparison with other historic buildings, the modelling of the case study was simpler, because it is characterized by geometries that are more regular and a design that is more standardized. For the elements that have nevertheless irregular geometries and a predominant sculptural and/or ruined character, such us statues or archaeological ruins, a different modelling workflow was adopted. Once segmented and classified, the point clouds related to these objects were processed (cleaning-up, closing) and saved as meshes in OBJ file format, using software programs such as 3DReshaper. As aforementioned, the meshes can be either converted into BIM/IFC format and enriched with attributes, or imported into the BIM platform using visual programming tools, such as Dynamo. For the elements with complex geometries that can be express mathematically, such as arches and vaults, were tested either "adaptive components" or NURBS (Non Uniform Rational Basis-Splines), which can generate surfaces that follow the scans without significant geometric deviations due to their ability to interpolate points. Imported into the BIM authoring software program, they can be used to create parametric objects.

The BIM model was constantly checked to avoid conflicts and overlaps (e.g. using Autodesk Naviswork). It can be consequently used for facilitating the characterization and mapping of conservation and degradation states of architectural elements. The data collected 
through visual evaluations and photographic classifications, possibly supported by specific building investigations, sampling and sample analysis, can be linked, inserted, processed in the BIM platform and provide a picture of the current situation of the building, leading to the pre-diagnosis phase.

Specific software programs, such as Dalux or Autodesk BIM 360, allowed sharing the created BIM model and the related documentation on different devices. Through these sharing platforms, it is possible, among other things, to add metadata, to incorporate augmented reality, to facilitate the space and asset management. To expand the capabilities of facilities management systems into BIM, also ARCHIBUS released recently a plug-in called Smart Client Extension for Revit.

Moreover, the BIM model was used also to carry out some simulations for automating and/or facilitating decision-making processes. Using plug-ins such as Relux, for instance, it was possible to speed up lighting design and calculations.

\section{CONCLUSIONS}

This paper presents some of the results of an application of a BIM-based lifecycle-oriented approach to information modelling and management of an existing building set in an urban historical context. Investigating different digital tools (BIM, GIS, DBMS) in the preparatory phases of a building restoration project, it aimed at facilitating knowledge sharing, interdisciplinary collaboration and decision-making processes for territorial transformations, as well as management, monitoring and promotion of cultural heritage. After the definition of a shared coding/cataloguing system and a relational model for database management, the created database was populated while the documentary and archival research was carried out and the gathered documents processed. Once a storage solution for graphical/non-graphical data and documentation was set-up and geo-referencing procedures and common coordinates were identified, a topographical and geometric survey was carried out and a BIM-oriented 3D model in support of urban, architectural and historical analysis was created.

This approach is becoming strategically important, especially in countries such as Italy, which have a vast built heritage with remarkable historical and architectural values, and are experimenting a reduction in new construction projects. Although complex, as well as time and skill consuming, it offers multiple additional benefits, both in the professional and research practices, which come from the modelling process and the possibility of constant upgrades (Stober et al. [28]).

Taking into account the Ministerial Decree 560/2017, which defines modalities and timing of the BIM introduction in Italy, as well as the growing demand for specialized professionals throughout the world, there is a clear need for further researches and trainings in this field. For this purpose, universities, schools and research institutes, which can produce and disseminate knowledge and innovation, as well as investigate historic contexts and promote the territory as a whole, need to collaborate closely with professionals and software houses. (Biagini and Arslan [3]). According to Volk et al. [29], nowadays major researches focus on the development of cost-efficient and highly automated BIM creation based on laser scanning or photogrammetry, while future researches may include material- or texture-based recognition and non-destructive testing methods. Furthermore, also clear and consequent modelling workflows and standards are required and have to be investigated and defined.

Since the BIM method is closer to the construction process as the CAD one, it can contribute to the interpretation of the built heritage and the assessment of alternatives and decisions. According to Centofanti et al. [30], a BIM-oriented approach can be considered as an interoperable process of knowledge, design, maintenance and management of a building/infrastructure project. For historic buildings, it can support the integration of the 
different disciplinary contributions during the analysis, restoration and/or maintenance, as well as communication and promotion processes. The interventions on the architectural heritage and historic contexts can be viewed as stages of a whole lifecycle and parts of a single management process.

The difficulties of such a paradigm shift, which changes the focus from the product to the process, lie also in the organisational/cultural aspects and not only in the technological ones. Taking duly into account change management theories and models, conditions for greater interdisciplinary collaboration should be created. Some of the barriers that are limiting the adoption of this approach can be addressed through new forms of contract, which should be identified and tested.

An effective and efficient management of data can lead to better project decisions and deliveries, allowing higher quality and lower costs, more sustainability and fewer risks, as well as combining preservation with promotion of the cultural heritage, transformation with protection of the territory.

\section{ACKNOWLEDGEMENTS}

This paper presents some of the results achieved thanks to the previous experiences and studies of the author, as well as the project "SPIDEr" (Strategies for Planning and Integrated Development of Urban Cultural Contexts) carried out at the Institute for Archaeological and Monumental Heritage (IBAM) of the Italian National Research Council (CNR) (now "Istituto di Scienze del Patrimonio Culturale" (ISPC)). The latter was financed by the European Structural and Investment Funds (PO FSE Sicilia 2020 - Avviso 11/2017). The author would like to thank all those who have contributed in various ways.

\section{REFERENCES}

[1] Becker, T., Kolbe, T.H. \& Nagel, C., Semantic 3D modeling of multi-utility networks in cities for analysis and 3D visualization. Progress and New Trends in 3D Geoinformation Sciences, Lecture Notes in Geoinformation and Cartography, eds J. Pouliot, S. Daniel, F. Hubert \& A. Zamyadi, Springer: Berlin, Heidelberg, pp. 41-62, 2012.

[2] Gigliarelli, E., Calcerano, F., Calvano, M., Ruperto, F., Cessari, L. \& Sacco, M., Integrated numerical analysis and building information modeling for cultural heritage. Building Simulation Applications BSA 2017: Proceedings of the 3rd IBPSA-Italy Conference, Bozen-Bolzano, 8-10 Feb. 2017, eds G. Pernigotto, A. Gasparella, V. Corrado, A. Prada \& F. Patuzzi, BU Press: Bozen/Bolzano, 2017.

[3] Biagini, C. \& Arslan, P., Industrial heritage in the historical neighbourhood: BIM strategies for urban regeneration. DISEGNARECON: Advanced Technologies for Historical Cities Visualization, 11(21), 2018.

[4] Kiviniemi, A., Built environment and our digital future. Proceedings of the 4th International Workshop: “When Social Science meets LEAN and BIM”, Huddersfield, 28-29 Jan. 2016, eds P. Tzortzopoulos \& Y. Zhang, The University of Huddersfield Press: Huddersfield, p. 9, 2016.

[5] Succar, B., Building information modelling maturity matrix. Handbook of Research on Building Information Modelling and Construction Informatics: Concepts and Technologies, eds J. Underwood \& U. Isikdag, IGI Publishing, Information Science Reference, pp. 65-103, 2010. DOI: 10.4018/978-1-60566-928-1.ch004.

[6] Ciribini, A.L.C., Mastrolembo Ventura, S. \& Bolpagni, M., La validazione del contenuto informativo è la chiave del successo di un processo BIM-based. Territorio Italia, Agenzia delle Entrate: Rome, 2016. DOI: 10.14609/Ti_2_15_1i. 
[7] Saygi, G. \& Remondino, F., Management of architectural heritage information in BIM and GIS: State-of-the-art and future perspectives. International Journal of Heritage in Digital Era, 2(4), pp. 695-713, 2013.

[8] Kolbe, T.H. \& Plümer, L., Bringing GIS and CA(A)D together: Integrating 3D city models emerging from two different disciplines. GIM International, 18(7), pp. 12-15, 2004.

[9] Song, Y. et al., Trends and opportunities of BIM-GIS integration in the architecture, engineering and construction industry: A review from a spatio-temporal statistical perspective. ISPRS International Journal of Geo-Information, 6(12), p. 397, 2017. DOI: 10.3390/ijgi6120397.

[10] Chenaux, A. et al., Review of 3D GIS for use in creating Virtual Historic Dublin. ISPRS: International Archives of the Photogrammetry, Remote Sensing and Spatial Information Sciences, XLII-2/W9, pp. 249-254, 2019.

DOI: 10.5194/isprs-archives-XLII-2-W9-249-2019.

[11] Murphy, M., Pavia, S., Cahill, J., Lenihan, S. \& Corns, A., An initial design framework for Virtual Historic Dublin. ISPRS: International Archives of the Photogrammetry, Remote Sensing and Spatial Information Sciences, XLII-2/W11, pp. 901-907, 2019. DOI: 10.5194/isprs-archives-XLII-2-W11-901-2019.

[12] López, F.J., Lerones, P.M., Llamas, J., Gómez-García-Bermejo, J. \& Zalama, E., A review of Heritage Building Information Modeling (H-BIM). Multimodal Technologies Interact, 2(2), p. 21, 2018. DOI: 10.3390/mti2020021.

[13] Murphy, M., McGovern, E. \& Pavia, S., Historic Building Information Modelling (HBIM). Structural Survey, 27(4), pp. 311-327, 2009.

DOI: $10.1108 / 02630800910985108$.

[14] Murphy, M., Dore, C., McCarthy, S., Brechin, F., Casidy, C. \& Dirix, E., Structural simulations and conservation analysis: Historic Building Information Model (HBIM). ISPRS: International Archives of the Photogrammetry, Remote Sensing and Spatial Information Sciences, XL-5/W4, pp. 351-357, 2015.

DOI: 10.5194/isprsarchives-XL-5-W4-351-2015.

[15] Gigliarelli, E., Calcerano, F. \& Cessari, L., Heritage BIM, numerical simulation and decision support systems: An integrated approach for historical buildings retrofit. Energy Procedia, Proceedings of the CLIMAMED 2017: Mediterranean Conference of HVAC Historical Buildings Retrofit in the Mediterranean Area, Matera, 12-13 May 2017, eds F.R. d'Ambrosio Alfano, L. Mazzarella \& P. Romagnoni, Elsevier: Amsterdam, 133, pp. 135-144, 2017. DOI: 10.1016/j.egypro.2017.09.379.

[16] Brumana, R., Oreni, D., Cuca, B., Binda, L., Condoleo, P. \& Triggiani, M., Strategy for integrated surveying techniques finalized to interpretive models in a Byzantine church, Mesopotam, Albania. International Journal of Architectural Heritage, Conservation, Analysis, and Restoration, 8(6), pp. 886-924, 2014.

DOI: 10.1080/15583058.2012.756077.

[17] Thomson, C.P.H., From Point Cloud to Building Information Model. Capturing and processing survey data towards automation for high quality $3 \mathrm{~d}$ models to aid a BIM process. Doctoral thesis, UCL (University College London), 2016. http://discovery.ucl.ac.uk/id/eprint/1485847.

[18] Graham, K., Chow, L. \& Fai, S., Level of detail, information and accuracy in building information modelling of existing and heritage buildings. Journal of Cultural Heritage Management and Sustainable Development, 8(4), pp. 495-507, 2018.

DOI: 10.1108/JCHMSD-09-2018-0067. 
[19] Banfi, F., Building information modelling: A novel parametric modeling approach based on 3D surveys of historic architecture. EuroMed 2016: Digital Heritage. Progress in Cultural Heritage: Documentation, Preservation, and Protection, eds M. Ioannides, et al., Springer: Cham, Lecture Notes in Computer Science, 10058, pp. 116127, 2016. DOI: 10.1007/978-3-319-48496-9 10.

[20] Brusaporci, S., Cinti Luciani, S. \& Mingucci, R., B.I.M. dimensions: Postfactum. DISEGNARECON: B.I.M. Dimensions, 9(16), 2016.

[21] Biagini, C. \& Donato, V., Building Object Models (BOMs) for the documentation of historical building heritage. Proceedings of the 5th Congreso Internacional de Expresión Gráfica en Ingeniería, Arquitectura y Carreras Afines y XI Congreso Nacional de Profesores de Expresión Gráfica en Ingeniería, Arquitectura y Carreras Afines, Rosario, 1-3 Oct. 2014, eds H.C. Lomonaco \& S. Barba, CUES: Rosario, pp. 442-448, 2014.

[22] Calabrese, G.S., Alcuni documenti inediti sul monastero di San Nicolò l'Arena di Catania nella seconda metà dell'Ottocento. Archivio Storico per la Sicilia Orientale/Società di Storia Patria per la Sicilia Orientale, Year 95, Booklets I-III, pp. 283-326, 1999.

[23] De Carlo, G., Un Progetto per Catania: Il recupero del Monastero di San Nicolò l'Arena per l'Università, SAGEP Editrice: Genova, 1988.

[24] Nazarena, B. \& Riccardo, R., Il BIM per gli edifici storici, potenzialità e criticità. Il caso del Duomo di Parma. Proceedings of the 21st National Conference ASITA 2017, Salerno, 21-23 Nov. 2017, 2017.

[25] Paris, L. \& Wahbeh, W., Rilievo e rappresentazione delle geometrie parametriche per l'HBIM. DISEGNARECON: B.I.M. Dimensions, 9(16), pp. 101-109, 2016.

[26] Brusaporci, S., Ruggeri, G., Maiezza, P., Tata, A., Trizio, I. \& Giannangeli, A., AHBIM per l'analisi stratigrafica dell'architettura storica. Restauro Archeologico (RA), 27(1), pp. 112-131, 2018. DOI: 10.13128/RA-23463.

[27] Yang, X., Koehl, M. \& Grussenmeyer, P., Mesh-to-BIM: From segmented Mesh elements to BIM model with limited parameters. ISPRS: International Archives of the Photogrammetry, Remote Sensing and Spatial Information Sciences, XLII-2, pp. 1213-1218, 2018. DOI: 10.5194/isprs-archives-XLII-2-1213-2018.

[28] Stober, D., Žarnić, R., Penava, D., Turkalj Podmanicki, M. \& Virgej-Đurašević, R., Application of HBIM as a research tool for historical building assessment. Civil Engineering Journal, 4(7), pp. 1565-1574, 2018. DOI: 10.28991/cej-0309195.

[29] Volk, R., Stengel, J. \& Schultmann, F., Building Information Models (BIM) for existing buildings: Literature review and future needs. Automation in Construction, 38, pp. 109-127, 2014. DOI: 10.1016/j.autcon.2013.10.023.

[30] Centofanti, M., Brusaporci, S. \& Maiezza, P., Tra "HistoricalBIM" ed HeritageBIM: Building information modeling per la documentazione dei Beni Architettonici. Proceedings of ReUSO 2016. IV Convegno Internazionale sulla documentazione, conservazione e recupero del patrimonio architettonico e sulla tutela paesaggistica, Pavia, 6-8 Oct. 2016, eds S. Parrinello \& D. Besana, Edifir: Firenze, 2016. 